\title{
Disorders of Sleep and Aggression Trait in Women Associated: What Underlies Staying "Woke"?
}

\section{Donna K Hobgood*}

College of Medicine, University of Tennessee Medical Units, Tennessee, USA

${ }^{*}$ Corresponding author: Donna K Hobgood, College of Medicine, University of Tennessee Medical Units, Chattanooga, Tennessee, USA, Tel: +423-488-8589; Fax: 423-899-8066; E-mail: donnahmd@gmail.com

Received: 09 Apr, 2019 | Accepted: 06 May, 2019 | Published: 13 May, 2019

Citation: Hobgood DK (2019) Disorders of Sleep and Aggression Trait in Women Associated: What Underlies Staying "Woke"? Gynecol Women's Health Res 1(1): dx.doi.org/10.16966/2689-3096.112

Copyright: (C) 2019 Hobgood DK. This is an open-access article distributed under the terms of the Creative Commons Attribution License, which permits unrestricted use, distribution, and reproduction in any medium, provided the original author and source are credited.

\begin{abstract}
Narcolepsy is a sleep disorder where the patient falls asleep unwillingly. It is thought to be related to hyper functioning central sleep centers in the brain. Sleep apnea is a disorder of breathing disruption during sleep. Genes of the dopamine system have been implicated with high dopamine: norepinephrine ratio. Since dopamine has also been associated with personality traits, the hypothesis we studied herein was that patients with narcolepsy and sleep apnea would score low in catecholamine settings causing aggression trait. We found that narcolepsy and sleep apnea diagnoses showed significantly lower aggression trait using an online test. The conclusion is that narcolepsy and sleep apnea patients are not aggressive in personality, and since aggressiveness is related to sympathetic nervous system activity, this would be predictable given the role of sympathetic nervous system in wakefulness.
\end{abstract}

This result sheds light on the connection of sleep and wakefulness and the autonomic nervous system as well as the central nervous system. It also enlightens on personality as a window to physiology in health and in illness.

\section{Introduction}

Personality is largely genetic with catecholamine genes showing associations with many traits [1-20], including dopamine receptors both D2 like receptors as well as D1 like receptors. Dopamine metabolizing enzymes such as monoamine oxidase type A as well as monoamine oxidase type $\mathrm{B}$, catechol-O-methyltransferase has been found associated with many personality traits. Personality trait systems include the Cloninger traits of Novelty Seeking, Reward Dependence, Risk Avoidance and Persistence, and the Big Five traits of Openness to Experience, Conscientiousness, Extraversion, Agreeableness, and Neuroticism all of which have shown many genetic correlates. Still a consensus has not been reached about personality traits and genes just as little consensus exists about correlations between disease and personality traits.

A physiologic and genetic system showing promise of insights into health is one called NPA Personality Theory, a genetic theory based on sympathetic and parasympathetic nervous system correlates as causative of personality. Aggression as a correlate of sympathetic nervous system is one of three traits that are widespread. Narcissism correlates with the parasympathetic nervous system. Perfectionism affects the autonomic nervous system and thus modulates both Aggression and Narcissism in some individuals. Every individual putatively has one or more of these traits. Some individuals have modifiers of each trait some of which are associated with discernible unusual behavior patterns. A personality test as well as full explanation of the theory for these traits is available online [21-24].
Sleep is related to the central nervous system with dopamine as a prime factor in regulation of sleep and wakefulness. High dopamine activity seems related to sleep states, and high norepinephrine activity seems related to wakefulness [25-32]. Lower availability of DRD3 receptors was associated with daytime somnolence in Parkinson disease patients suggesting that high dopamine neurotransmission caused somnolence through activation at certain dopamine receptors [31]. Rodent studies have demonstrated also dopamine receptor agonists both centrally and peripherally $[29,30]$ as productive of somnolence $[26,28,32]$.

Since these neurotransmitters are also related to personality traits, there may be clinical correlation with personality traits and sleep patterns. Many genes and illnesses have shown correlation with various sleep related diagnoses. Indeed, if sleep has physiologic correlates with the autonomic nervous system, a personality survey based on autonomic nervous system function would be correlated to sleep diagnoses, and specifically lower aggression trait as a correlate of sympathetic nervous system with higher norepinephrine and epinephrine balance would be related to sleep apnea or narcolepsy incidence. Since sleep and aggression are correlated with sympathetic tone in opposite directions our hypothesis was that patients with diagnosis of sleep disorders such as sleep apnea and narcolepsy would show low prevalence of aggression trait.

\section{Method}

With a view of conducting a pilot study on personality and 
diagnoses, patients seen in the office over a year's time of one obstetrician-gynecologist were given opportunity to take the online NPA personality test. At the time of their office visit, all diagnoses as well as demographic factors and physician assessment of patient status as to these personality traits were recorded on an Excel spreadsheet with over 250 queries regarding a broad range of established diagnoses in general health as well as gynecologic health available for selection.

This study was not submitted to Institutional Review Board as the patient data was de-identified for the study and dealt with standard clinical data collected in taking history in an ob-gyn office.

After the data collection phase was completed, patients with diagnosis of narcolepsy or sleep apnea who had taken the online personality tests were to be reviewed for their results as to whether they had shown Aggression trait on their tests.

Patients were offered the online NPA personality test as a part of their office visit with the invitation stating that a study was being done to explore the relationships between personality and diagnoses. An Excel spread sheet was configured to list all diagnoses of each patient and was logged by the physician at the time of each patient's office visit.

Statistical analysis planned was chi square for difference between study group and entire population. The online test center returned the test to the physician who recorded the result and related the result to the patient with an invitation to answer any questions about the result. After the year of testing was done, correlations were to done between diagnoses and personality results in the entire group. Based on literature review on personality and illness, the expectation was that there would be correlations between low aggression trait and illness in a wide variety of types in our patient population of women.

\section{Results}

There were 4028 patients seen in the office during the study period of a year. 1235 patients took the online personality test. In looking at all patients, 50\% showed aggression trait. Age showed minimal effect of lessening aggression trait. Eight patients had diagnosis of narcolepsy of them one took the online personality test while 18 patients had diagnosis of sleep apnea of whom ten took the online test. Of those patients with diagnosis of sleep apnea who took the test none had results showing aggression trait though of those ten patients one patient had ambiguous results on online test while the office assessment was non-aggressive personality. Because all study patients showed the expected result of not having aggression trait, there was no need for chi square test to compare study group with entire population 50 percent of whom had aggression trait result on the online test.

Results of this pilot study unrelated to sleep apnea or narcolepsy are described in previous article, but in summary, those with any medical diagnosis (688 of 1275 patients) and those with any psychiatric diagnosis (275 of 1275 patients) differed significantly on personality test from others. Details were published previously and detailed several differences in groups as well as exploring likely genetic correlates as causes of these differences.

This present paper explores possible meanings of score differences in a subset of patients in the above pilot study, patients with disorders of wakefulness.

\section{Discussion and Conclusion}

Sleep disorder may have implications for such diverse pathologies as sudden death in general, sudden infant death syndrome, fetal demise, neonatal respiratory distress, automobile and other transportation-related accidents, dementia, Alzheimer's disease and end-of-life process and many others[33-84]. The central commonality in these diverse pathologies could be catecholamine and other neurotransmitter processes such as the genetically controlled ratio of dopamine and norepinephrine activity emanating from the locus coeruleus in the midbrain and the processes of the sleep center in the ventral tegmental area [32,47]. Dopamine beta hydroxylase alleles which provide dopamine quantitative dominance fuels all downstream dopamine dominance, a situation producing more cognitive activity as opposed to more musculoskeletal action. In fact, somnolence as an extreme is found in individuals who evidence less trend to musculoskeletal activity, true to the model. Another example of an effect of this dopamine: norepinephrine dichotomy is the attention deficit hyperactivity diagnosis to include the carelessness allowing accidental injury and impulsive misbehaviors, where a shift toward norepinephrine as opposed to dopamine has presumably happened upstream. So pathologies of both extremes in the dopamine: norepinephrine ratio exists though more pathologies do appear to be related to the high dopamine: norepinephrine ratio. Further examples can be noted in the case of sudden death in adults, fetuses or children where high dopamine balance appears to be operative. In the example of Alzheimer's disease, other dementias and end of life events for the extremely elderly, the loss of norepinephrine seems at the heart of the sleep that overcomes wakefulness eventuating in the cessation of breathing and the end of life.

Just as genetic causes of illness are becoming better understood so are personality genetics becoming better elucidated. And they may be correlated $[66,77]$.

Our study did not address genetic polymorphisms of patients to correlate with personality and illness but instead studied personality as a proxy for genetic polymorphism. Since $50 \%$ of personality is genetic, this approach has some validity though with some limitations given both the shared and non-shared environmental correlates of personality. Added to that limitation is the lack of consistency of genetic studies of personality as many studies fail to yield replication in subsequent studies. Similarly, many studies of genetic causes of illness find a complex interweaving of genetic and environmental causes that seems to approximate the 50/50 division of nature $v s$ nurture found in personality causation. So with some strong limitations in this type of endeavor, this pilot study was planned and carried out and yielded the expected outcomes in illness and personality associations and relationships in general and with many specific topics such as the one in focus in this paper, that of sleep apnea and narcolepsy.

A guiding hypothesis seems to be that neurons in the sleep centers are affected by genes of the dopamine system such that high dopamine activity promotes sleep and high norepinephrine activity promotes wakefulness. And in personality genetics higher dopamine seems to promote non-aggressiveness and higher norepinephrine activity seems to promote aggressiveness. This scheme seems to play out in the central nervous system as well as in the autonomic nervous system with the principle that sympathetic nervous system seems more active in fight or flight aggressive actions while parasympathetic nervous system seems more active in resting functions such as gastrointestinal functions.

Because of the central nervous system and the peripheral nervous system control of all physiology, disorders associated with sleep disorders also include schizophrenia and autism. Dopamine has been found central to pathophysiology of both schizophrenia and autism, and the dopamine: norepinephrine circuitry especially the locus coeruleus as the prime site of action of dopamine beta hydroxylase, the enzyme determining the dopamine: norepinephrine ratio is 
thought central [33]. Dopamine Beta Hydroxylase gene (DBH) has linkage with other genes such as the ABO blood group (ABO), and $\mathrm{ABO}$ blood group maternal-fetal incompatibility as been found to be associated with lower hippocampal volume in schizophrenia $[33,34]$. Schizophrenia has been noted through basic physiologic variants to be associated with a wide range of health issues starting with cardiovascular and renal illness and including metabolic issues such as osteoporosis [55]. Vitamin D deficiency was found in a Dutch study to be 4.7 times more common among those with bipolar disorder, schizophrenia or schizoaffective disorder [58]. Osteoporosis may be related through Vitamin D genetics having as it does strong interactions with midbrain dopamine: norepinephrine ratio. Thus osteoporosis is associated with schizophrenia and other psychoses $[44-45,56-60,64,74,75]$. And similarly autism has been found to have associations with osteoporosis as well [62-64]. Environmental causes of osteoporosis have not been found to explain this, and the finding holds for all ethnicities and genders studied. So instead of being related to environmental or socioeconomic variation, these linkages of such diverse pathologies as osteoporosis and schizophrenia would logically have a major commonality genetically.

These associations have been thought to be a manifestation of evolutionary concepts demonstrating the concept of tradeoffs [61] that is, illnesses occurring in clusters have continued genetically because of some tradeoff advantages that are linked to the illnesses by virtue of their common biochemistry and in fact brain chemistry. Thus an evolutionarily wrought larger volume in cerebral brain centers allows more neurotransmission with some accompanying pathologic chemistries producing collateral damage. The relatively rapid attainment of larger neo-cortex would logically carry deficiencies since the ancestral organism had survived untold generations without the larger neo-cortex, and given that mutations are statistically speaking detrimental for the organism, a bad outcome would be assumed. In the case of the larger neo-cortex and accompanying increase in neurotransmission, damages include that of sleep apnea, narcolepsy, osteoporosis, and putatively such far-reaching illnesses as schizophrenia, autism, Alzheimer's disease, sudden death and in fetuses and infants, sudden death, and various anomalies.

The allele for dopamine beta hydroxylase that produces high dopamine: norepinephrine ratio is not the ancestral allele and appears to be on the ascendancy in human populations. So since any evolutionary event has to be explained by changes in the production of progeny that survive to produce progeny, the issue of high dopamine: norepinephrine ratio producing individuals with seemingly more pathologies may demonstrate that fitness has its drawbacks or tradeoffs that have to be faced. And downstream dopamine related genes seem to fine tune such that the benefits of high dopamine neurotransmission can be retained while the risks ameliorated. One example of that would be the metabolizing enzyme COMT appearing to be manifesting an evolutionary path where the lower metabolizer is not the ancestral state but is instead the evolutionary winner in human populations. Additionally, dopamine receptors with polymorphisms producing less activity make up for the profound suppression of adenylyl cyclase caused by the D2 type receptor activation. So understanding one neurotransmitter role is fraught with the complexity of checks and balances upstream and downstream. The production of surviving progeny would appear to always be the goal of evolution, and even a very high burden of disease from a genetic background that allows surviving progeny may survive even with high disease burden. Such may be the case of the high dopamine: norepinephrine ratio in the midbrain.
Progeny that survive may live shorter lives, but reproduction is the prime feature. Diseases such as schizophrenia and autism shorter lives and decrease progeny. Why does schizophrenia continue to exist? Why is autism in fact on the rise? The answer seems to be in the tradeoffs whereby these pathologies are hard-wired by the large neo-cortex that was selected in early man. A set of environmental challenges existed. Man's life was short and brutal, and a larger neo-cortex with higher dopamine: norepinephrine ratio for memory and analysis of environment survived.

The fetal pathologies have their genesis in the earliest of embryonic events. And it is this timing of the creation of pathologies that pinpoints brain chemical and anatomic embryology as the cause, specifically the roots of the autonomic nervous system in the midbrain and medulla oblongata. The formation of the neural tube is the first discernible event in embryology and therefore the genesis of all body forming events that follow. So downstream phenomenon reflect early embryonal events.

Sudden infant death syndrome of unknown cause as well as fetal demise has been thought to result from central nervous system midbrain malfunction [49,50,52]. Central sleep centers through a high dopamine: norepinephrine ratio connects third trimester fetal demise with sudden infant death syndrome $[50,84]$. A prime genetic cause of this is low activity Dopamine Beta Hydroxylase (DBH) as it codes for an enzyme that determines that ratio $[48,53]$. And because of linkage disequilibrium of DBH with $\mathrm{ABO}$ blood group gene [83], correlation is found not just with previously mentioned pathologies such as schizophrenia, autism and osteoporosis but also with $\mathrm{ABO}$ and sudden infant death and fetal demise [34-36,38-40,42-44] as well as with $\mathrm{ABO}$ gene and fetal anomalies such as congenital heart disease [35,36] and spina bifida [38] as well as cleft lip and cleft palate [42-44]. $\mathrm{ABO}$ gene has also been associated with osteoporosis [38-40]. Most studies have trended toward finding that non-O ABO groups are more likely to be affected when maternal $A B O O$ is involved, this related to the higher antibody formation of $\mathrm{ABO} O$ maternal $v$ s $\mathrm{ABO}$ non-O fetuses. And those fetuses with dopamine predominance have more suppression effects as they have more dopamine neurotransmission at the D2 like receptors. This may explain the lack of neuro-resilience eventuating in more pathology at all fetal stages, certainly supporting miscarriage and fetal anomalies as well as more schizophrenia and autism in surviving fetuses.

Because personality trait testing is genetically associated with brain factors, this can be used as a clinical inroad into behavior and broader medical factors [33-83].

Our finding that sleep disorders of sleep apnea and narcolepsy are associated with lack of aggressiveness in personality is consistent with this theoretical framework used to explore the complex function of sleep and wakefulness.

The study was extremely limited as only one patient of the 8 patients with diagnosis of narcolepsy took the online test and only 10 of 18 patients with diagnosis of sleep apnea took the online test. Furthermore, the test used to test for aggression trait in personality is invalidated. Aggression trait is defined many different ways by different researchers and has subcategories such as state aggression, reactive aggression, and many others. In some studies it is related to such concepts as impulsivity, hyperactivity, and other many traits. The NPA system used in our study aimed to elicit fight or flight traits built on traditional theories about the sympathetic nervous system and behavior. 
This study was a pilot study to generate hypotheses, and these hypotheses will need much further study before any conclusions can be reached on such topics. Results of analysis of this pilot study suggested significant difference in personality in patients with diagnoses versus those without diagnoses both for medical diagnoses and for psychiatric diagnoses [80]. Our study showed a trend toward low aggression trait consistent with research supporting association of several diagnoses with each other and with causative catecholamine activities in osteoporosis, in third trimester fetal demise, fetal and neonatal disease/anomalies [35-37,41-43,49,52,56], schizophrenia $[34,35,46-48,51,54-61,79]$ and autism $[33,51,62,63]$ as well as Vitamin $\mathrm{D}$ deficiency with ABO genes [45,46,77], Alzheimer's [76] bone fracture [62], and autoimmune diseases [61].

Schizophrenia studies are extensive given the profound morbidities that individuals, families and societies accrue related to these individuals. Some authorities have thought of autism as a childhood form of schizophrenia, just to highlight the profound disturbances noted. But schizophrenia typically has onset in late puberty. Medical advances are significant in ability to control symptoms be they negative (lack of motivation) or positive (distortions of reality) and were heralded by the finding that antihistaminic preparations offered some control of symptoms. This led to development of dopamine blocking medications. The lack of specificity in blockade has made these treatments problematic. So a clear central cause of schizophrenia and autism is most to be sought. Starting at the beginning of the organism, in embryology seems logical. The developmental, antenatal, viral or other causes can be placed in their right perspective.

And in the case of higher aggression trait, this genetic set related to dopamine: norepinephrine ratio includes ADD or ADHD [65] and Parkinson's disease [46] as well as some types of autoimmune diseases [61], and alertness deficits with resultant accidental injury [62].

This group of diagnoses may share several genetic causes from pleiotropy so that the study of these issues as a genetic anlage has promise to be rewarding [61].

\section{References}

1. Cloninger CR, Svrakic DM, Przybeck TR (1993) A psychobiological model of temperament and character. Arch Gen Psychiatry 50: 975990.

2. Keller MC, Coventry WL, Heath AC, Martin NG (2005) Widespread evidence for non-additive genetic variation in Cloninger's and Eysenck's personality dimensions using a twin plus sibling design. Behav Genet 35: 707-721.

3. Gerra G, Zaimovic A, Timpano M, Zambelli U, Delsignore R, et al. (2000) Neuroendocrine correlates of temperamental traits in humans. Psychoneuroendocrinology 25: 479-496.

4. Tochigi M, Otowa T, Hibino $\mathrm{H}$, Kato $\mathrm{C}$, Otani T, et al. (2006) Combined analysis of association between personality traits and three functional polymorphisms in the tyrosine hydroxylase, monoamine oxidase A, and catechol-O-methyltransferase genes. Neurosci Res 54: $180-185$.

5. McDermott R, Tingley D, Cowden J, Frazzetto G, Johnson DDP (2009) Monoamine oxidase A gene (MAOA) predicts behavioral aggression following provocation. Proc Natl Acad Sci (PNAS) 106: 2118-2123.

6. Gabbert TG (2009) The application of the theory of narcissism in criminal proceedings (forensic theory of narcissism). Arch Kriminol 224: $116-126$.
7. Filipenko ML, Beilina AG, Alekseyenko OV, Dolgov VV, Kudryavtseva NN (2002) Repeated experience of social defeats increases serotonin transporter and monoamine oxidase A mRNA levels in raphe nuclei of male mice. Neurosci Lett 321: 25-28.

8. Roy A, De Jong J, Linnoila M (1989) Extraversion in pathological gamblers. Correlates with indexes of noradrenergic function. Arch Gen Psychiatry 46: 679-681.

9. Kaplan JR, Manuck SB, Fontenot MB, Mann JJ (2002) Central nervous system monoamine correlates of social dominance in cynomolgus monkeys (Macaca fascicularis). Neuropsychopharmacology 26: 431443.

10. Fernandez X, Meunier-Salaün MC, Mormede P (1994) Agonistic behavior, plasma stress hormones, and metabolites in response to dyadic encounters in domestic pigs: interrelationships and effect of dominance status. Physiol Behav 56: 841-847.

11. Fano E, Sánchez-Martín JR, Arregi A, Castro B, Alonso A, et al. (2001) Social stress paradigms in male mice: variations in behavior, stress and immunology. Physiol Behav 73: 165-173.

12. Singh J, Chowdhury S, Maiti BR (1982) Adrenomedullary hormonal stimulation and hyperglycemia following intermale aggression in the bandicoot rat. Endokrinologie 3: 347-349.

13. Summers $\mathrm{CH}$, Greenberg N (1995) Activation of central biogenic amines following aggressive interaction in male lizards, Anolis carolinensis. Brain Behav Evol 45: 339-349.

14. Cacho R, Fano E, Areso P, Garmendia L, Vegas O, et al. (2003) Endocrine and lymphoproliferative response changes produced by social stress in mice. Physiol Behav 78: 505-512.

15. Newton TL, Bane CM, Flores A, Greenfield J (1999) Dominance, gender, and cardiovascular reactivity during social interaction. Psychophysiology 36: 245-252.

16. Newton TL, Watters CA, Philhower CL, Weigel RA (2005) Cardiovascular reactivity during dyadic social interaction: the roles of gender and dominance. Int J Psychophysiol 57: 219-228.

17. Gramer M, Berner M (2005) Effects of trait dominance on psychological and cardiovascular responses to social influence attempts: the role of gender and partner dominance. Int J Psychophysiol 55: 279-289.

18. Newton TL (2009) Cardiovascular functioning, personality, and the social world: the domain of hierarchical power. Neurosci Biobehav Rev 33: 145-159.

19. Björkqvist $K$ (2001) Social defeat as a stressor in humans. Physiol Behav 73: 435-442.

20. Buckholtz JW, Callicott JH, Kolachana B, Hariri AR, Goldberg TE, et al. (2008) Genetic variation in MAOA modulates ventromedial prefrontal circuitry mediating individual differences in human personality. Mol Psychiatry 13: 313-324.

21. Benis AM (1985) Toward self and sanity: on the genetic origins of the human character. Psychological Dimensions, The University of California, USA 19.

22. Benis AM, Hobgood DK (2011) Dopamine receptor DRD3 codes for trait aggression as Mendelian recessive. Med Hypotheses 77: 11081110.

23. Benis A (1990) A theory of personality traits leads to a genetic model for borderline types and schizophrenia. Specul Sci Technol 13: 167175. 
24. Pagano G, Molloy S, Bain PG, Rabiner EA, Chaudhuri KR, et al. (2016) Sleep problems and hypothalamic dopamine $\mathrm{D} 3$ receptor availability in Parkinson disease. Neurology 87: 2451-2456.

25. Oishi Y, Suzuki Y, Takahashi K, Yonezawa T, Kanda T, et al. (2017) Activation of ventral tegmental area dopamine neurons produces wakefulness through dopamine D2-like receptors in mice. Brain Struct Funct 222: 2907-2915.

26. Oporto GH, Bornhardt T, Iturriaga V, Salazar LA (2018) Single nucleotide polymorphisms in genes of dopaminergic pathways are associated with bruxism. Clin Oral Investig 22: 331-337.

27. Barik S, de Beaurepaire R (2005) Dopamine D3 modulation of locomotor activity and sleep in the nucleus accumbens and in lobules 9 and 10 of the cerebellum in the rat. Prog Neuropsychopharmacol Biol Psychiatry 29: 718-726.

28. Clemens S, Sawchuk MA, Hochman S (2005) Reversal of the circadian expression of tyrosine-hydroxylase but not nitric oxide synthase levels in the spinal cord of dopamine D3 receptor knockout mice. Neuroscience 133: 353-357.

29. Clemens S, Hochman S (2004) Conversion of the Modulatory Actions of Dopamine on Spinal Reflexes from Depression to Facilitation in D3 Receptor Knock-Out Mice. J Neurosci 24: 11337-11345.

30. Rissling I, Geller F, Bandmann O, Stiasny-Kolster K, Körner Y, et al. (2004) Dopamine receptor gene polymorphisms in Parkinson's disease patients reporting "sleep attacks". Mov Disord 19: 12791284.

31. Lagos P, Scorza C, Monti JM, Jantos H, Reyes-Parada M, et al. (1998) Effects of the D3 preferring dopamine agonist pramipexole on sleep and waking, locomotor activity and striatal dopamine release in rats. Eur Neuropsychopharmacol 8: 113-120.

32. London EB (2018) Neuromodulation and a Reconceptualization of Autism Spectrum Disorders: Using the Locus Coeruleus Functioning as an Exemplar. Front Neurol 9: 1120.

33. Freedman $D$, Deicken $R$, Kegeles LS, Vinogradov $S$, Bao $Y$, et al. (2011) Maternal-fetal Blood Incompatibility and Neuromorphologic Anomalies: Preliminary Findings. Prog Neuropsychopharmacol Biol Psychiatry 35: 1525-1529.

34. Irvine DG, Miyashita H (1965) Blood Types in Relation to Depressions and Schizophrenia. Can Med Assoc J 92: 551-554.

35. Zu B, You G, Fu Q, Wang J (2017) Association between ABO Blood Group and Risk of Congenital Heart Disease: A 6-year large cohort study. Sci Rep 7: 42804.

36. Feingold J, Feingold N, Bois E (1980) Spina bifida and anencephaly. Geographic correlation with the HLA system. Tissue Antigens 15: 318-324.

37. Kaur M (2014) Association between $A B O$ blood group and osteoporosis among postmenopausal women of North India. Homo 65: 516-521.

38. Lu BB, Li KH (2011) Association between ABO blood groups and osteoporosis severity in Chinese adults aged 50 years and over. J Int Med Res 39: 929-933.

39. Choi JW, Pai SH (2004) Associations between ABO blood groups and osteoporosis in postmenopausal women. Ann Clin Lab Sci 34: 150153.

40. Cerný M, Fára M, Hrivnáková J (1991) Aetiological, modifying and lethal factors in cleft lip and palate. Acta Chir Plast 33: 72-86.
41. Chzhan SSh, Khén DF (1990) The incidence of the development of congenital clefts of the upper lip and palate in relation to blood group among the inhabitants of the provinces of the People's Republic of China. Stomatologiia (Mosk) 69: 71-72.

42. Balgir RS (1986) Serological and biochemical genetic markers in congenital cleft lip and cleft palate anomalies. Isr J Med Sci 22: 572575 .

43. el-Kholy MS, Abdel Mageed FY, Farid FA (1992) A genetic study of Vitamin $D$ deficiency rickets: 2-sex differences and ABO typing. J Egypt Public Health Assoc 67: 213-222.

44. Spitsyn VA, Okuneva EG, Novikov PV, Tashpulatov Rlu, Guseva EV (1991) Genetic aspects of Vitamin D-deficient rickets: genetic markers of blood. Genetika 27: 2002-2012.

45. Tang S, Yao B, Li N, Lin S, Huang Z (2018) Association of Dopamine Beta-Hydroxylase Polymorphisms with Alzheimer's Disease, Parkinson's Disease and Schizophrenia: Evidence Based on Currently Available Loci. Cell Physiol Biochem 51: 411-428.

46. Sun Z, Ma Y, Li W, He J, Li J, et al. (2018) Associations between the DBH gene, plasma dopamine $\beta$-hydroxylase activity and cognitive measures in Han Chinese patients with schizophrenia. Schizophr Res 193: 58-63.

47. Venner A, Todd WD, Fraigne J, Bowery $H$, Eban-Rothschild A, et al. (2019) Newly identified Sleep-wake and circadian circuits as potential therapeutic targets. Sleep 5.

48. Hui L, Han M, Yin GZ, Zhang $Y$, Huang XF, et al. (2017) Association between DBH 19bp insertion/deletion polymorphism and cognition in schizophrenia with and without tardive dyskinesia. Schizophr Res 182: $104-109$

49. Wildner H, Gierl MS, Strehle M, Pla P, Birchmeier C (2008) Insm1 (IA1) is a crucial component of the transcriptional network that controls differentiation of the sympatho-adrenal lineage. Development 135: 473-481.

50. Lim KC, Lakshmanan G, Crawford SE, Gu Y, Grosveld F, et al. (2000) Gata3 Loss Leads to Embryonic Lethality Due to Noradrenaline Deficiency of the Sympathetic Nervous System. Nat Genet 25: 209212.

51. Naviaux RK, Zolkipli Z, Wang L, Nakayama T, Naviaux JC, et al. (2013) Antipurinergic Therapy Corrects the Autism-Like Features in the Poly(IC) Mouse Model. PLoS One 8: e57380.

52. Baker CN, Gidus SA, Price GF, Peoples JN, Ebert SN (2015) Impaired Cardiac Energy Metabolism in Embryos Lacking Adrenergic Stimulation. Am J Physiol Endocrinol Metab 308: E402-E413.

53. Bolstad G, Helle KB, Serck-Hanssen G (1980) Heterogeneity in the Adrenomedullary Storage of Catecholamines, ATP, Calcium and Releasable Dopamine Beta-Hydroxylase Activity. J Auton Nerv Syst 2: 337-354.

54. Chen YH, Lee HC, Lin HC (2009) Prevalence and Risk of Atopic Disorders Among Schizophrenia Patients: A Nationwide Population Based Study. Schizophr Res 108: 191-196.

55. Orellana G, Rodríguez M, González N, Durán E (2017) The Association of Schizophrenia with Chronic Non Transmissible Diseases. Rev Med Chil 145: 1047-1053.

56. Cui J, Liu H, Shao J, Xu DM, Wang Y, et al. (2018) Prevalence, Risk Factors and Clinical Characteristics of Osteoporosis in Chinese in Patients with Schizophrenia. Schizophr Res 195: 488-494. 
57. Boerman R, Cohen D, Schulte PF, Nugter A (2016) Prevalence of Vitamin D Deficiency in Adult Outpatients With Bipolar Disorder or Schizophrenia. J Clin Psychopharmacol 36: 588-592.

58. Gomez L, Stubbs B, Shirazi A, Vancampfort D, Gaughran F, et al. (2016) Lower Bone Mineral Density at the Hip and Lumbar Spine in People with Psychosis Versus Controls: a Comprehensive Review and Skeletal Site-Specific Meta-analysis. Curr Osteoporos Rep 14 249-259.

59. González-Blanco L, Greenhalgh AMD, Garcia-Rizo C, Fernandez-Egea E, Miller BJ, et al. (2016) Prolactin Concentrations in AntipsychoticNaïve Patients with Schizophrenia and Related Disorders: A MetaAnalysis. Schizophr Res 174: 156-160.

60. Tseng PT, Chen YW, Yeh PY, Tu KY, Cheng YS, et al. (2015) Bone Mineral Density in Schizophrenia: An Update of Current Meta-Analysis and Literature Review Under Guideline of PRISMA. Medicine (Baltimore) 94: e1967.

61. Crespi BJ, Go MC (2015) Diametrical Diseases Reflect EvolutionaryGenetic Tradeoffs: Evidence From Psychiatry, Neurology, Rheumatology, Oncology and Immunology. Evol Med Public Health 2015: 216-253.

62. Neumeyer AM, O'Rourke JA, Massa A, Lee $H$, Lawson EA, et al. (2015) Brief Report: Bone Fractures in Children and Adults with Autism Spectrum Disorders. J Autism Dev Disord 45: 881-887.

63. Croen LA, Zerbo O, Qian Y, Massolo ML, Rich S, et al. (2015) The Health Status of Adults on the Autism Spectrum. Autism 19: 814823

64. Zylstra RG, Porter LL, Shapiro JL, Prater CD (2008) Prevalence of Osteoporosis in Community-Dwelling Individuals with Intellectual and/or Developmental Disabilities. J Am Med Dir Assoc 9: 109-113.

65. Miano S, Amato N, Foderaro G, Pezzoli V, Ramelli GP, et al. (2018) Sleep Phenotypes in Attention Deficit Hyperactivity Disorder. Sleep Med.

66. Fink AM, Bronas UG, Calik MW (2018) Autonomic Regulation During Sleep and Wakefulness: A Review with Implications for Defining the Pathophysiology of Neurological Disorders. Clin Auton Res 28: 509 518.

67. Hombali A, Seow E, Yuan Q, Chang SHS, Satghare P, et al. (2018) Prevalence and Correlates of Sleep Disorder Symptoms in Psychiatric Disorders. Psychiatry Res.

68. Li Y, Wang W, Lin P, Lu H, Zhang Y, et al. (2015) Study on the Psychologic Status and Personality Traits of Patients with Obstructive Sleep Apneahypopnea Syndrome. Zhonghua Er Bi Yan Hou Tou Jing Wai Ke Za Zhi 50: 587-593.

69. Sforza E, de Saint Hilaire Z, Pelissolo A, Rochat T, Ibanez V (2002) Personality, Anxiety and Mood Traits in Patients with Sleep-Related Breathing Disorders: Effect of Reduced Daytime Alertness. Sleep Med 3: 139-145.

70. Fernandez-Mendoza J, Calhoun SL, Bixler EO, Karataraki M, Liao D, et al. (2011) Sleep Misperception and Chronic Insomnia in the General
Population: Role of Objective Sleepduration and Psychological Profiles. Psychosom Med 73: 88-97.

71. Cassel W, Stephan S, Ploch T, Peter JH (1989) Psychological Aspects of Sleep Related Disorders of Respiratory Control. Pneumologie 43: 625-629.

72. Koffel E, Watson D (2009) Unusual Sleep Experiences, Dissociation and Schizotypy: Evidence for a Common Domain. Clin Psychol Rev 29: 548-559.

73. Nevsímalová S, Sonka K, Spacková N, Pretl M, Hofmannová R (2002) Excessive Daytime Somnolence and its Psychosocial Sequelae. Sb Lek 103: 51-57.

74. Bobić J, Cvijetić S, Barić IC, Satalić Z (2012) Personality Traits, Motivation and Bone Health in Vegetarians. Coll Antropol 36: 795800

75. Mondello S, Kobeissy F, Mechref Y, Zhao J, Talih FR, et al. (2018) Novel Biomarker Signatures for Idiopathic REM Sleep Behavio Disorder: A Proteomic and System Biology Approach. Neurology 91: e1710-e1715.

76. Lehmann DJ, Refsum H, Warden DR, Medway C, Wilcock GK, et al. (2011) The Vitamin D receptor gene is associated with Alzheimer's disease. Neurosci Lett 504: 79-82.

77. Madrid-Valero JJ, Ordoñana JR, Klump KL, Burt SA (2018) Children Sleep and Antisocial Behavior: Differential Association of Sleep with Aggression and Rule-Breaking. J Abnorm Child Psychol 47: 791-799.

78. Duffy KB, Ray B, Lahiri DK, Tilmont EM, Tinkler GP, et al. (2019) Effects of Reducing Norepinephrine Levels via DSP4 Treatment on Amyloid- $\beta$ Pathology in Female Rhesus Macaques (Macaca Mulatta). J Alzheimers Dis 68: 115-126.

79. Belbin O, Morgan K, Medway C, Warden D, Cortina-Borja M, et al (2019) The Epistasis Project: A Multi-Cohort Study of the Effects of BDNF, DBH, and SORT1 Epistasis on Alzheimer's Disease Risk. J Alzheimers Dis 68: 1535-1547.

80. Hobgood DK (2011) Personality and Illness: Genetic Connections? Med Hypotheses 76: 89-93.

81. Fry PS, Debats DL (2009) Perfectionism and the Five-Factor Personality Traits as Predictors of Mortality in Older Adults. J Health Psychol 14: 513-524.

82. Tentolouris N, Liatis S, Katsilambros N (2006) Sympathetic System Activity in Obesity and Metabolic Syndrome. Ann N Y Acad Sci 1083 129-152.

83. Wilson AF, Elston RC, Siervogel RM, Tran LD (1988) Linkage of a Gene Regulating Dopamine-Beta-Hydroxylase Activity and the ABO Blood Group Locus. Am J Hum Genet 42: 160-166.

84. Denoroy L, Gay N, Gilly R, Taylt J, Pasquier B, et al. (1987) Catecholamine Synthesizing Enzyme Activity in Brainstem Areas from Victims of Sudden Infant Death Syndrome. Neuropediatris 18: 187-190. 